\title{
A site-specific study on the measurement of sorption coefficients for radionuclides
}

\author{
A. A. Dalvi · S. D. Kumar • A. V. R. Reddy
}

Received: 12 July 2012/Revised: 14 January 2013/Accepted: 5 March 2013/Published online: 29 March 2013

(C) Islamic Azad University (IAU) 2013

\begin{abstract}
A study on the potential of geological media from the vicinity of the mining site in Tummalapalle region of Andhra Pradesh in India for retardation of radionuclide migration in groundwater was conducted. The studies included the measurement of sorption coefficients for six radionuclides, uranium, thorium, lead, bismuth, radium and polonium, between two groundwater simulants and two site-specific samples of geological media. Initial parametric studies involving chemical composition, $\mathrm{pH}$, calcium carbonate and organic carbon contents of both geological media and ground water simulants were carried out. Significant differences in sorption coefficients were observed as a result of varying $\mathrm{pH}$, calcium carbonate and presence of trace quantities of organic contents in simulant solutions. For example, uranium has a hundred fold lower distribution coefficient in the case of simulant solution having higher carbonate content. Similarly, in the case of the geological media having higher calcium carbonate and organic carbon contents, higher distribution coefficients were obtained for all radionuclides. Among the six radionuclides studied thorium showed the largest and radium the smallest distribution coefficient values for the soil samples assessed. The site-specific sorption coefficients will be used for contaminant transport study.
\end{abstract}

Keywords Bismuth · Groundwater · Polonium - Radium . Soil · Thorium · Uranium

\footnotetext{
A. A. Dalvi · S. D. Kumar $(\bowtie)$ - A. V. R. Reddy

Analytical Chemistry Division, Bhabha Atomic Research

Centre, Mumbai 400085, India

e-mail: sangdk@barc.gov.in
}

\section{Introduction}

An important mechanism in retarding the movement of radionuclide in groundwater is sorption. The term is used to encompass all mechanisms pertinent to interaction between radionuclides and geomedia that include ion exchange, adsorption, and precipitation. The environmental behavior of the natural radionuclides presents a challenging problem for their regular monitoring in the atmosphere and hydrosphere. It is important to understand the distribution pathways, mobility, transfer of these radionuclides in the environment because the information could be used as a natural analogue for the long-term behaviour of materials and processes in the development and testing of the models (Davis et al. 1999; Butler and Wheater 1999a; Butler et al. 1999; Thiessen et al. 1999; Mortvedt 1994; Tome et al. 2003; Petterson et al. 1993). Several investigations have been performed on mobilization of natural radionuclides (such as ${ }^{238} \mathrm{U}$ and ${ }^{226} \mathrm{Ra}$ ) in different environmental compartments (soil, plant, and water), as well as the transfer between them, at different uranium mining sites around the world (Krizman et al. 1995; Fernandes et al. 1996; Maity et al. 2011).

The behavior of radionuclides in the environment can be well understood by studying through either laboratory investigations under controlled conditions or through comprehensive field studies. The number of significant influencing parameters, their variability in the field and differences in experimental methods result in as much as seven orders of magnitude variability in measured distribution coefficient $\left(K_{\mathrm{d}}\right)$ values reported in the literature. This variability makes it much more difficult to derive generic $K_{\mathrm{d}}$ values for radionuclides and therefore, it is recommended that $K_{\mathrm{d}}$ values be measured for site-specific conditions. Hence, in this study, site-specific soils from 
Tummalapalle region of Andhra Pradesh in India, as well as synthetic simulant solutions were used to obtain $K_{\mathrm{d}}$ values for radionuclides.

Tummalapalle uranium deposit is located in Vemula Mandal of Andhra Pradesh at a distance of about $70 \mathrm{~km}$ from the district headquarter, Cuddapah. The deposit is covered under Survey of India Toposheet Nos. 57J/3 and $57 \mathrm{~J} / 7$ between latitudes $14^{\circ} 18^{\prime} 36^{\prime \prime} \mathrm{N}$ and $14^{\circ} 20^{\prime} 20^{\prime \prime} \mathrm{N}$ and longitudes $78^{\circ} 15^{\prime} 16^{\prime \prime} \mathrm{E}$ and $78^{\circ} 18^{\prime} 03.3^{\prime \prime} \mathrm{E}$ (Fig. 1). Predicting the transfer of radionuclides in the environment for normal release, accidental, disposal or remediation scenarios and to assess exposure requires the knowledge of several generic parameter values. One of the key parameters in environmental assessment is the solid liquid distribution coefficient, $K_{\mathrm{d}}$, which is used to predict radionuclide-soil interaction and its subsequent transport in the soil.

In the present work, two site-specific soils and simulant solutions were characterized for various physico-chemical parameters, such as chemical composition, $\mathrm{pH}$, calcium carbonate $\left(\mathrm{CaCO}_{3}\right)$ and organic carbon content. Radionuclides uranium $(\mathrm{U})$, thorium $(\mathrm{Th})$, lead $(\mathrm{Pb})$, bismuth

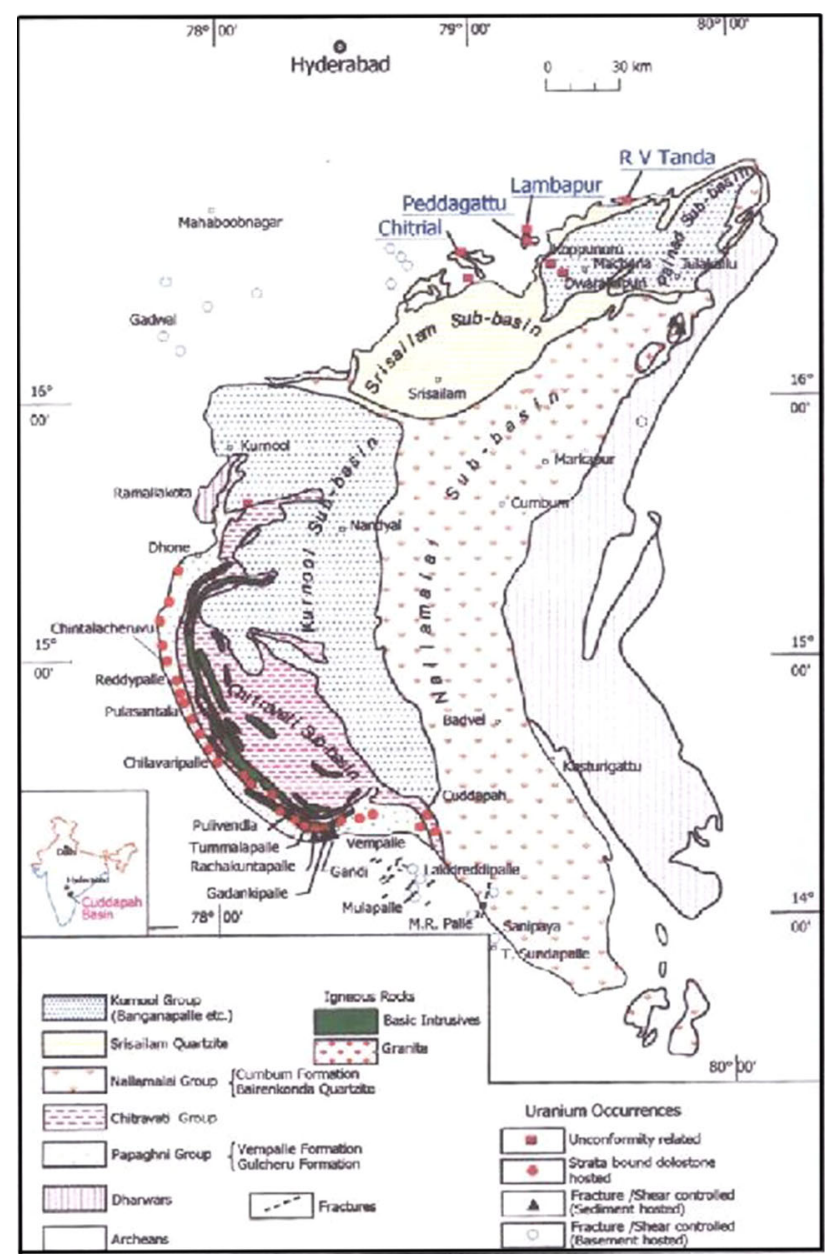

Fig. 1 Geological map of cuddapah basin
(Bi), radium ( $\mathrm{Ra})$ and polonium $(\mathrm{Po})$ were systematically assessed for their behavior in this soil/simulant solutions by batch sorption method. The $K_{\mathrm{d}}$ values obtained for different radionuclides have been discussed in details in the paper. The present study was carried out at Analytical Chemistry Division, BARC, Mumbai, India, during the period February 2010 to April 2012.

\section{Materials and methods}

\section{Geological media}

The geological samples used in this work were collected from the tailings near an uranium mine at Tummalapalle region of Andhra Pradesh. The locations of the site are shown in the map in Fig. 1. Two sampling sites were selected and the samples were taken from $20 \mathrm{~cm}$ depth. The samples were oven-dried at $105{ }^{\circ} \mathrm{C}$, crushed, homogenized and sieved. The soil samples having size fraction below $2 \mathrm{~mm}$ were used for studies and labeled as soils 1 and 2. The soil samples were oven-dried at $105{ }^{\circ} \mathrm{C}$ for $24 \mathrm{~h}$ prior to $K_{\mathrm{d}}$ studies.

\section{Characterization of soil samples}

The $\mathrm{pH}$ was measured using Oakton bench top $\mathrm{pH} 510$ meter as per IS procedure 2720 Part $26 . \mathrm{CaCO}_{3}$ content was determined by titrimetry as per IS procedure 2720 Part 23 and confirmed using thermogravimetry-differential thermogravimetry (TG-DTG) (Ntezsch, Germany, Model STA 4099). Total and organic carbon contents were determined by Euro EA carbon analyzer. The elemental composition of both the soil samples was determined using EDXRF (Jordan Valley EX-3600M) by relative method using IAEA Reference standards.

\section{Groundwater simulants}

Two simulant solutions of different ionic strengths, one of low ionic strength (Water 1) and another similar to that of the site (Water 2), were prepared (as per EPA 821-R-020013) for $K_{\mathrm{d}}$ studies. The use of simulants offer the advantage of providing a reproducible matrix which allows for direct comparison of $K_{\mathrm{d}}$ data generated in different laboratories. The simulant solutions were filtered through a $0.45 \mu \mathrm{m}$ polycarbonate membrane before their use.

\section{Characterization of simulated groundwater samples}

The simulated groundwater samples were analyzed for $\mathrm{pH}$, total organic and inorganic carbon, cations and anions. The $\mathrm{pH}$ of simulated ground water samples was measured using 
Oakton bench top pH 510 meter. Total organic and inorganic carbon was determined using ANATOC-II series carbon analyzer (SGE, Australia). The cations and anions present in the simulated ground water samples were determined using Flame Atomic Absorption Spectrometry (Chemito AA 203) and ion chromatography (IC Metrohm 733), respectively.

Sorption experiments for the determination of distribution coefficient values $\left(K_{\mathrm{d}}\right)$ in soil samples

Oven-dried soil sample $(1 \mathrm{~g})$ was taken in $50 \mathrm{~mL}$ polycarbonate centrifuge tubes. It was repeatedly washed with simulated ground water till the $\mathrm{pH}$ of the supernatant solution remained unchanged. This soil sample was equilibrated with $30 \mathrm{~mL}$ of simulated ground water spiked with one of the elements of interest. Distribution coefficient measurements in the simulated groundwater were carried out for each element separately to eliminate competing ion effects. For $\mathrm{U}, \mathrm{Th}, \mathrm{Pb}$ and $\mathrm{Bi}$, samples were spiked with their respective stable isotope standard solutions $\left(1 \mathrm{mg} \mathrm{mL}^{-1}\right)$, whereas for $\mathrm{Ra}$ and $\mathrm{Po}$, their respective radiotracers viz ${ }^{226} \mathrm{Ra}$ and ${ }^{210} \mathrm{Po}$ were used. The solution $\mathrm{pH}$ was adjusted to its initial value by the addition of dilute $\mathrm{NaOH} / \mathrm{HNO}_{3}$ in small increments. The experimental tubes were then gently shaken at room temperature on a mechanical shaker for a period of $72 \mathrm{~h}$ and the sample was centrifuged by high-speed centrifugation ( $\mathrm{RCF}>5,000 \mathrm{~g}$ ) for $30 \mathrm{~min}$. Supernatant solution was removed and analyzed for the element of interest. These sorption experiments were carried out for each element/radionuclide.

\section{Determination of $U, T h, P b$ and $B i$}

The supernatant solutions were treated with conc. $\mathrm{HNO}_{3}$ to destroy any organic matter, if present. The solutions were analyzed using ICP-MS (VG PQ ExCell, VG Elemental, UK).

\section{Determination of $R a$}

Radium-226 $\left({ }^{226} \mathrm{Ra}\right)$ in a known aliquot of the above solutions was co-precipitated with lead sulphate. The precipitate was dissolved in EDTA and ${ }^{226} \mathrm{Ra}$ was separated from possible interfering radionuclides using a micro precipitation of barium sulphate. The solution was centrifuged and the precipitate was taken on a stainless steel planchet and dried under IR. Ra concentration in the sample was determined by counting gross- $\alpha$ using a $\mathrm{ZnS}$ scintillation detector.

\section{Determination of Po}

Polonium-210 $\left({ }^{210} \mathrm{Po}\right)$ in a known aliquot of supernatant solution was determined after depositing it on $\mathrm{Ag}$-planchet under stirred conditions from hot $\left(70-80{ }^{\circ} \mathrm{C}\right)$ acidified solution for a period of $1 \mathrm{~h}$. The planchet was air-dried and Po was determined by counting gross- $\alpha$ using a ZnS scintillation detector.

Radionuclide sorption was expressed as a distribution coefficient $\left(K_{\mathrm{d}}\right.$ in $\left.\mathrm{mL} \mathrm{g}^{-1}\right)$ using the equation:

$K_{\mathrm{d}}=\frac{\left(C_{i}-C_{\mathrm{f}}\right)}{C_{\mathrm{f}}} \cdot \frac{V}{m}$

where $C_{\mathrm{i}}$ and $C_{\mathrm{f}}$ are the initial and final activities/concentration of radionuclide/element in the aqueous phase, $V$ is the volume of aqueous phase ( $30 \mathrm{~mL})$ and $m$ is the mass of soil $(1 \mathrm{~g}) . K_{\mathrm{d}}$ has units of $\mathrm{mL} \mathrm{g}^{-1}$.

\section{Results and discussion}

The most likely process that leads to the release of radionuclides from mining site or a radioactive waste repository in a geological medium is the transport by groundwater. The simplest and common parameter for modeling the transport of radionuclides in geologic media is the soilwater distribution coefficient $\left(K_{\mathrm{d}}\right)$. The radionuclides chosen for the present study are natural radionuclides; namely, $\mathrm{U}, \mathrm{Th}, \mathrm{Pb}, \mathrm{Bi}, \mathrm{Ra}$ and Po. The factors that affect the distribution coefficient $\left(K_{\mathrm{d}}\right)$ value for a particular radionuclide are the radionuclide's solubility and the availability of adsorption sites on the solid phase. Higher $K_{\mathrm{d}}$ values will be found in systems with larger numbers of appropriate adsorption sites while dissolved species with higher solubilities will have lower $K_{\mathrm{d}}$ values. A given set of conditions including $\mathrm{pH}$, particle size, radionuclide concentrations, and groundwater simulant composition was defined prior to starting the work and maintained throughout. The effect of $\mathrm{pH}$ is extremely important in both the solution chemistry and the adsorption mechanism involved in the $K_{\mathrm{d}}$ for a given geological medium. The $\mathrm{pH}$ values of $7.78 \pm 0.02$ and $8.42 \pm 0.02$ of groundwater simulants ( 1 and 2 ), respectively, were chosen as being representative of field $\mathrm{pH}$ measurements of natural groundwaters in the Tummalapalle region of Andhra Pradesh (Table 1). The TIC measurements and composition analysis showed higher hardness in the case of simulated groundwater 2 as compared to the simulated groundwater 1 (Table 1).

The $\mathrm{pH}$ values of the soil samples were found to be $6.49 \pm 0.02$ and $7.10 \pm 0.02$, respectively, for soils 1 and 2 (Table 2). Besides $\mathrm{pH}$, soil organic matter has a significant impact on the distribution coefficient values. It consists of humus and nonhumus substances. The polycarboxylic functional groups of fulvic and humic acids present in the soils form strong complexes with metal ions. The TOC measurements and $\mathrm{CaCO}_{3}$ analysis of soil samples showed that both organic carbon and calcium 
Table 1 Physico-chemical parameters of simulated groundwater samples

\begin{tabular}{lcc}
\hline Ions & Ground water $1\left(\mathrm{mg} \mathrm{L}^{-1}\right)$ & Ground water $2\left(\mathrm{mg} \mathrm{L}^{-1}\right)$ \\
\hline TOC & $3.4 \pm 0.1$ & $1.5 \pm 0.1$ \\
$\mathrm{TIC}$ & $16.0 \pm 0.3$ & $23.0 \pm 0.5$ \\
$\mathrm{Na}^{+}$ & $30.3 \pm 0.2$ & $34.9 \pm 0.2$ \\
$\mathrm{~K}^{+}$ & $2.7 \pm 0.1$ & $9.3 \pm 0.1$ \\
$\mathrm{Mg}^{+2}$ & $7.2 \pm 0.1$ & $58.4 \pm 0.1$ \\
$\mathrm{Ca}^{+2}$ & $16.6 \pm 0.3$ & $31.2 \pm 0.6$ \\
$\mathrm{Cl}^{-}$ & $1.7 \pm 0.1$ & $176.0 \pm 3.5$ \\
$\mathrm{SO}_{4}{ }^{2-}$ & $35.2 \pm 0.7$ & $24.0 \pm 0.5$ \\
$\mathrm{NO}_{3}{ }^{-}$ & $0.7 \pm 0.1$ & $7.5 \pm 0.2$
\end{tabular}

The $\mathrm{pH}$ values of simulated groundwater 1 and simulated groundwater 2 were $7.78 \pm 0.02$ and $8.42 \pm 0.02$, respectively

carbonate content of soil 2 were higher as compared to the soil 1(Table 2).

Figures 2, 3 present a comparison of $K_{\mathrm{d}}$ values obtained for different radionuclides for different soil and groundwater combinations. The effect of soil and groundwater composition on the $K_{\mathrm{d}}$ values has been discussed in the order of their magnitude of $K_{\mathrm{d}}$ values of the radionuclides.

\section{Thorium}

The $K_{\mathrm{d}}$ values for Th were 1-2 order of magnitude higher than all other radionuclides for both the soils and groundwater combinations (Figs. 2, 3). This may be attributed to the presence of thorium ion as $\mathrm{Th}^{4+}$ ion in the groundwater. Owing to this, quadrivalent thorium ions tend to be highly surface active and are strongly retained by particulate materials as compared to divalent ions of other radionuclides. The reviews on the behaviour of Th in soils also support our data (Lieser et al. 1990; Sheppard 1980; Harmsen and Haan 1980; Adams et al. 1959). In addition, the presence of higher organic content in soil 2 resulted in significantly higher $K_{\mathrm{d}}$ values (1.3-3 times) due to the

Table 2 Physico-chemical parameters of soil samples

\begin{tabular}{|c|c|c|c|}
\hline \multicolumn{2}{|l|}{ Element } & \multirow{2}{*}{$\frac{\text { Soil } 1(\%)}{1.49 \pm 0.03}$} & \multirow{2}{*}{$\frac{\text { Soil } 2(\%)}{2.23 \pm 0.05}$} \\
\hline $\mathrm{CaCO}_{3}$ & By titrimetry & & \\
\hline & By TG-DTG & $1.51 \pm 0.02$ & $2.50 \pm 0.03$ \\
\hline \multicolumn{2}{|c|}{ Organic carbon } & $0.45 \pm 0.09$ & $0.62 \pm 0.06$ \\
\hline \multicolumn{2}{|l|}{$\mathrm{TiO}_{2}$} & $0.65 \pm 0.03$ & $1.08 \pm 0.02$ \\
\hline \multicolumn{2}{|l|}{$\mathrm{MnO}$} & $0.10 \pm 0.01$ & $0.14 \pm 0.01$ \\
\hline \multicolumn{2}{|l|}{$\mathrm{SiO}_{2}$} & $71.7 \pm 0.3$ & $38.7 \pm 0.2$ \\
\hline \multicolumn{2}{|l|}{$\mathrm{Al}_{2} \mathrm{O}_{3}$} & $13.2 \pm 0.2$ & $11.9 \pm 0.2$ \\
\hline \multicolumn{2}{|l|}{$\mathrm{Fe}_{2} \mathrm{O}_{3}$} & $6.1 \pm 0.2$ & $8.6 \pm 0.2$ \\
\hline \multicolumn{2}{|l|}{$\mathrm{K}_{2} \mathrm{O}$} & $2.6 \pm 0.1$ & $1.4 \pm 0.1$ \\
\hline
\end{tabular}

The $\mathrm{pH}$ values of soils 1 and 2 were $6.49 \pm 0.02$ and $7.10 \pm 0.02$, respectively
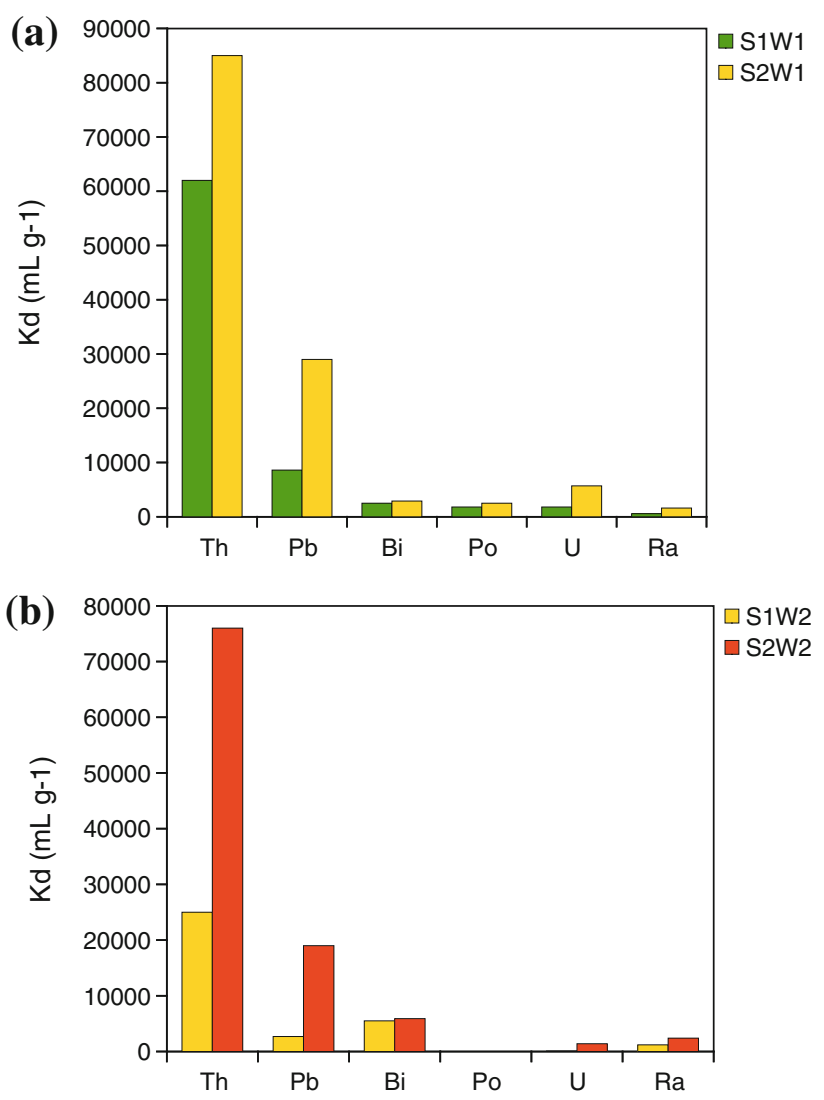

Fig. 2 Effect of soil composition on $K_{\mathrm{d}}$ values for different radionuclides in case of a simulated groundwater $1 \mathbf{b}$ simulated groundwater 2

complexation of thorium ions with soil organic matter. The $K_{\mathrm{d}}$ values of Th were higher for soil 2 for both the groundwater combinations (S2W1 and S2W2) as compared to soil 1 (S1W1 and S1W2) as can be seen from Fig. 2a, b. The $K_{\mathrm{d}}$ values of Th were found to be lowered by 2.4-1.2 times in groundwater 2 (Fig. 2b) due to the presence of higher carbonate content that leads to the formation of stable and soluble carbonate complex that decreases the sorption of thorium on to the soil matrix.

Lead

The $K_{\mathrm{d}}$ values for $\mathrm{Pb}$ were found to be higher than the $K_{\mathrm{d}}$ values for all other radionuclides except thorium. The sorption behavior of lead was found to be greatly affected by the presence of calcium and organic content in soil 2 . The $K_{\mathrm{d}}$ values were an order of magnitude higher in soil 2 as compared to soil 1 (Fig. 2a, b). Lead is generally present as the divalent cation and it can displace common soil cations such as those of potassium $\left(\mathrm{K}^{+}\right)$and calcium $\left(\mathrm{Ca}^{2+}\right)$ from exchange sites. Thus, sorption of $\mathrm{Pb}$ ions is facilitated on soil 2 by ion exchange and binding with organic ligands resulting in higher $K_{\mathrm{d}}$ values. Both these factors contribute to retardation of lead in geologic media. 

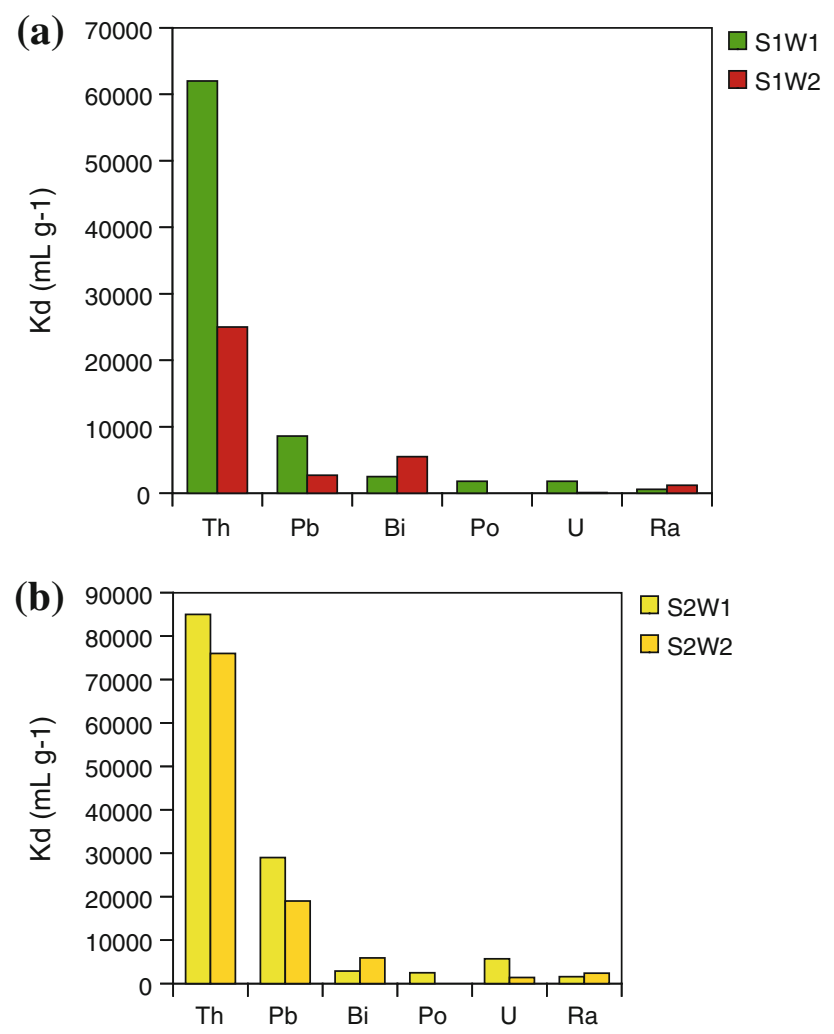

Fig. 3 Effect of groundwater composition on $K_{\mathrm{d}}$ values for different radionuclides in case of $\mathbf{a}$ soil $1 \mathbf{b}$ soil 2

In the case of simulated groundwater 2, the $K_{\mathrm{d}}$ values of $\mathrm{Pb}$ too were found to be lowered by 2.4-1.2 times (Fig. 2b) due to the presence of higher carbonate content which leads to formation of stable and soluble carbonate complex.

\section{Bismuth}

In general the $K_{\mathrm{d}}$ values obtained for bismuth were lower as compared to lead except in the case of simulated groundwater 2 (Fig. 2b). In the case of bismuth, the $K_{\mathrm{d}}$ values were found to be unaffected by the composition of soil (Fig. 2a, b). Bismuth is generally assumed to exist in natural environments in the +3 state and when in solution at neutral $\mathrm{pH}$ would be present as hydroxide complexes; predominately cationic and neutrally charged (Ames and Rai 1978). Sorption-desorption data for bismuth are scarce in the literature.

In the case of simulated groundwater 2 , the $K_{\mathrm{d}}$ values were found to be higher for both the soils and groundwater combinations (S1W2 and S2W2) as seen in Fig. 2b. This may be due to the formation of cationic complex of bismuth hydroxide at higher $\mathrm{pH}$. Hence, the sorption of $\mathrm{Bi}$ ions is facilitated by ion exchange. Similar observations were reported by Ulrich and Degueldre (Ulrich and Degueldre 1993) from their studies on the influence of the ionic strength and $\mathrm{pH}$ on the adsorption/desorption processes of lead, bismuth, and polonium on montmorillonite clay.

\section{Polonium}

Data obtained from our studies showed that the $K_{\mathrm{d}}$ value for Po was found to be of the same order as that for Bi for both the soils (Fig. 2a, b). This may be due to the proximity of Bi and Po in the periodic table. The $K_{\mathrm{d}}$ value for Po in soil 2 is slightly higher as compared to soil 1 (Fig. 2a, b). The higher organic content in soil 2 leads to the formation of organic complexes with Po (Maity et al. 2011).

Polonium compounds with +2 and +4 oxidation states have been reported, with the preferred oxidation state being +4 (Hansen 1970). Although Po is present as a quadrivalent ion, the $K_{\mathrm{d}}$ values of Po were an order of magnitude lower as compared to Th. This may be due to the tendency of polonium to adsorb or co-precipitate on the colloids suspended in ground water. The competition for sorption of Po between soil and groundwater results in intermediate values of $K_{\mathrm{d}}$. Vaaramaa et al. (2003) suggested that most of the ${ }^{210} \mathrm{Po}$ in the groundwater is bound in particles having high concentrations of $\mathrm{Fe}, \mathrm{Mn}$, and humus. It is also reported that iron and aluminum colloids and suspended particles may adsorb polonium. In comparison to radium and uranium, polonium was more prone to be associated with particles suspended in the groundwater.

\section{Uranium}

The $K_{d}$ values for $U$ were found to be lower as compared to $\mathrm{Th}, \mathrm{Pb}$ and $\mathrm{Bi}$ except for the soil 2 sample in groundwater 1 (Figs. 2,3). This is due to the higher mobility of uranium as compared to $\mathrm{Th}, \mathrm{Pb}$ and $\mathrm{Bi}$. The divalent ions of uranium form soluble complexes that tend to be mobile in groundwater. Similar observations have been reported in the literature on the behavior of $U$ in soil and in the geological environment (Sheppard 1980; Harmsen and Haan 1980; Paquette and Lemire 1981; Ollila 1985; Adams et al. 1959).The presence of higher organic content in soil 2 (Fig. 2a, b) resulted in complexation of the metal ion with soil organic matter and hence higher $K_{\mathrm{d}}$ values were obtained. The $K_{\mathrm{d}}$ values were found to be significantly lowered in simulated groundwater 2 (Fig. 2b). This was due to the presence of higher carbonate content which leads to formation of stable and soluble, uranyl carbonate complex that decreases the sorption of uranium on to the soil matrix.

\section{Radium}

The studies showed that $\mathrm{Ra}$ has the smallest distribution coefficient values (Figs. 2, 3) among the six radionuclides. This may be attributed to the formation of soluble Ra salts as reported by Lieser and Steinkopff (1989) that tend to be mobile in groundwater. The respective $K_{\mathrm{d}}$ values for soil 2 were higher than those for soil 1 (Fig. 2a, b), this may be 
due to the higher $\mathrm{Fe}$ and organic carbon content in soil 2 (Table 2) that provides sorption sites for Ra, resulting in larger $K_{\mathrm{d}}$ values. In a study of uranium mill tailings, Landa and Gray found that alkaline earth sulfate and hydrous ferric oxide solids are important sorption phases for radium (U.S.E.P.A 2004). The distribution coefficient values for Ra were found to be higher in case of simulated groundwater 2 (Fig. 3a, b) due to the formation of insoluble radium carbonate $\left(\mathrm{RaCO}_{3}\right.$ (aq) $)$ complex (solubility constant $5.01 \times 10^{-9} \mathrm{~mol} / \mathrm{L}$; Langmuir and Riese 1985).

\section{Conclusion}

A site-specific study was carried out to investigate the potential of geologic media on the retardation of radionuclide migration in groundwater. The soil-water sorption coefficient $\left(K_{\mathrm{d}}\right)$ for radionuclides was found to be affected by numerous geochemical parameters such as $\mathrm{pH}$, organic and inorganic carbon, iron oxides and other soil constituents, major ion chemistry and the chemical form of the radionuclide. Amongst the six radionuclides studied, the $K_{\mathrm{d}}$ values for thorium and radium corresponds to the maximum and minimum values. The ratio of $K_{\mathrm{d}}$ values for these radionuclides varies by two orders of magnitude for the soil samples analysed. A positive correlation was observed between soil organic and inorganic carbon and sorption coefficient for different radionuclides. It was observed that behaviour of uranium was strongly influenced by presence of carbonates. Site-specific studies are, therefore, very essential for assessing the possibility of ground water contamination by transport of radionuclides.

Acknowledgments The work is a part of coordinated DAE-BRNS project. The authors thank Dr. T. Mukherjee, Director Chemistry group for his constant encouragement and support in the present work. The authors are grateful to the coordinator Dr. G.G.Pandit and co-coordinator, Dr. Suchismita EAD, BARC for the constant support during the project. The authors are thankful to Dr. R. Verma for his continuous support and many fruitful discussions throughout the work. We wish to acknowledge Dr. Naina Raje, Dr. Sanjukta A. Kumar, Dr. D. N. Wagh, Ms. Nyoti Shenoy, Ms. Avanti Singh, Ms. Ayushi Dudhwadkar and Shri E K Unnikrishnan, ACD, BARC for their cooperation in providing various analytical data. We acknowledge Shri Anil Kumar, RSSD, BARC and Dr. Pramila Sawant, IDD, BARC for providing gross- $\alpha$ measurements.

\section{References}

Adams J, Osmond J, Rogers J (1959) The geochemistry of thorium and uranium. In: Ahrens H, Press F, Rankama K, Runcorn SK (eds) Physics and chemistry of the earth. Pergamon Press, NewYork, pp 298-348L

Ames L, Rai D (1978) Radionuclide Interactions with Soil and Rock Media. EPA 520/6-78-007, U.S. Environmental Protection Agency, Las Vegas, Nevada
Butler AP, Wheater H (1999) Modeling radionuclide transport and uptake in an integrated lysimeter experiment: II Application to sodium-22. J Environ Qual 28(6):1946-1956

Butler C, Aguero A, Edlund O, Elert M, Kirchner G, Raskob W, Sheppard M (1999) Performance assessment studies of models for water flow and radionuclide transport in vegetated soils using lysimeter data. J Environ Radioact 42:271-288

Davis P, Avadhanula M, Cancio D, Carboneras P, Coughtrey P, Johansson G, Little R, Smith G, Watkins BM (1999) BIOMOVS II: an international test of the performance of environmental transfer models. J Environ Radioact 42:117-130

Fernandes H, Franklin M, Veiga L, Freitas P, Gomiero L (1996) Management of uranium mill tailing: geochemical processes and radiological risk assessment. J Environ Radioact 30(1):69-95

Hansen W (1970) Polonium-210 in soils and plants. Special Report on U.S. Atomic Energy Commission Contract No. AT(11-1)-1733, COO-1733-11

Harmsen K, Haan F (1980) Occurrence and behaviour of uranium and thorium in soil and water. Neth J Agri Sci 8:40-62

Krizman M, Byrne A, Benedik L (1995) Distribution of 230Th in milling waste from the Zzirovski vrh uranium mine (Slovenia) and its radioecological implications. $J$ Environ Radioact 26:223-235

Langmuir D, Riese A (1985) The thermodynamic properties of radium. Geochim Cosmochim Acta 49:1593-1601

Lieser K, Steinkopff T (1989) Chemistry of radioactive iodine in the hydrosphere and in the geosphere. Radiochim Acta 46:49-55

Lieser K, Ament A, Hill R, Singh R, Stingl U, Thybusch B (1990) Colloids in groundwater and their influence on migration of trace elements and radionuclides. Radiochim Acta 49:83-100

Maity S, Mishra S, Bhalke S, Pandit G, Puranik V, Kushwaha H (2011) Estimation of distribution coefficient of polonium in geological matrices around uranium mining site. J Radio Nucl Chem 290(1):75-79

Mortvedt J (1994) Plant and soil relationships of uranium and thorium decay series radionuclides -a review. J Environ Qual 23:643-650

Ollila K (1985) Dissolution experiments of unirradiated uranium dioxide pellets. Nuclear waste commission of finish power companies. Report YJT-85-02

Paquette J, Lemire R (1981) A description of the chemistry of aqueous solutions of uranium and plutonium to $200^{\circ} \mathrm{C}$ using potential-pH diagrams. Nucl Sci and Engg 79:26-48

Petterson H, Hancock G, Johnston A, Murray A (1993) Uptake of uranium and thorium series radionuclides by the water lily, Nymphaea violacea. J Environ Radioact 19:85-108

Sheppard M (1980) The environmental behaviour of uranium and thorium. Atomic energy of Canada limited report, AECL-6795

Thiessen K, Thorne M, Maul P, Prohl G, Wheater H (1999) Modelling radionuclide distribution and transport in the environment. Environ Poll 100:151-177

Tome F, Blanco M, Lozano J (2003) Soil-to-plant transfer factors for natural radionuclides and stable elements in a Mediterranean area. J Environ Radioact 65:161-175

Ulrich H, Degueldre C (1993) The sorption of Pb-210, Bi-210, and Po-210 on montmorillonite-a study with emphasis on reversibility aspects and on the effect of the radioactive decay of adsorbed nuclides. Radiochim Acta 62:81-90

U.S.E.P.A (2004) Understanding Variation in Partition Coefficient, $K_{\mathrm{d}}$, Values. vol. III: Review of Geochemistry and Available $K_{\mathrm{d}}$ Values for Americium, Arsenic, Curium, Iodine, Neptunium, Radium, and Technetium. Office of Air and Radiation. (EPA402-R-04-002C):5.66 \& 5.68

Vaaramaa K, Lehto J, Ervann H (2003) Soluble and particle-bound 234,238U, 226Ra, and 210Po in ground waters. Radiochim Acta 91:21-27 